Revista Voluntas: Estudos sobre Schopenhauer - Vol. 3, Números 1 e 2 - $1^{\circ}$ e $2^{\circ}$ semestres de 2012 - ISSN: 2179-3786 - pp. 3-19.

\title{
"Prudentia" e o uso prático da razão em Schopenhauer ${ }^{1}$
}

\section{"Prudentia" and the practical use of reason by Schopenhauer}

\author{
Jorge Luiz Viesenteiner \\ Doutor em filosofia pela UNICAMP e professor do Programa de Pós-Graduação em Filosofia da \\ PUCPR. Membro do GIRN (Groupe International de Recherches sur Nietzsche) \\ pela Universidade de Greifswald/Alemanha. \\ E-mail: jvies@uol.com.br
}

\begin{abstract}
Resumo: O objetivo do texto é analisar o estatuto específico que a noção de prudentia recebe em Schopenhauer, notadamente se analisada no interior de Aforismos para sabedoria de vida. Trata-se da compreensão do uso prático da razão, no rigoroso sentido de uma sabedoria de vida ou de uma prudentia que definimos como diferenciação da diferenciação. Ao lado dessa hipótese principal, trata-se também de indicar outros horizontes interpretativos dos Aforismos, tais como sua estratégia literária marcada pela plausibilidade, a expressão 'grande pessimismo’ bem como o deslocamento da sabedoria estoica para as máximas aristotélicas.
\end{abstract}

Palavras-chave: Prudentia; Razão prática; Grande pessimismo; Plausibilidade.

Abstract: This article aims to analyze the specific status that the notion of prudentia receives by Schopenhauer, especially if analyzed within Aphorisms on the wisdom of life. It is the understanding about the practical use of reason in the strict sense of a wisdom of life or prudentia, that we define as differentiation of differentiation. Beside this main hypothesis, the article also contains other interpretative horizons regarding the Aphorisms, such as his literary strategy marked by plausibility, the term 'great pessimism' as well as the displacement from the stoic wisdom to some uses of the Aristotelian maxims.

Keywords: Prudentia; Practical reason; Great pessimism; Plausibility.

Na juventude rege a intuição, na velhice, a reflexão; dessa forma, aquela é a idade para a poesia, esta, mais para a filosofia.

(Schopenhauer, Aforismos para sabedoria de vida, p. 263)

\section{Considerações gerais}

Alguns debates contemporâneos sobre a filosofia de Schopenhauer no Brasil e na Europa se esforçam por esboçar um viés interpretativo, a propósito de um certo arrefecimento das conclusões ético-metafisicas radicalmente pessimistas, oriundas de $O$ mundo como vontade e como representação (doravante, apenas $O$ mundo), enfatizando o horizonte prático da razão schopenhaueriana,

\footnotetext{
${ }^{1}$ As hipóteses que esboçamos nesse artigo foram apresentadas originalmente na 6 a edição do Congresso Para saber mais Schopenhauer, realizado entre 29 de maio a 1 de junho de 2012, na Unicentro, em Guarapuava/PR. Deixo aqui registrado meus sinceros agradecimentos pelas discussões do congresso, que foram todas incorporadas ao texto, especialmente aos amigos Jair Barboza, Leandro Chevitarese, Ruy de Carvalho Rodrigues Júnior, bem como ao amigo Vilmar Debona, cujas reflexões contidas nesse texto são também frutos das interlocuções teóricas que mantivemos.
} 
notadamente quando se trata de ponderar sobre a vida prática do homem no mundo. Para além de nos filiarmos a quaisquer interpretações, nosso artigo, voluntária ou involuntariamente, flerta com tais possibilidades interpretativas menos pessimistas, especialmente quando lemos com mais atenção o texto dos Parerga publicado em 1851: os Aforismos para sabedoria de vida (doravante, apenas Aforismos).

Os Aforismos parecem ocupar um lugar à parte no corpus philosophicus schopenhaueriano e, a nosso ver, tanto no tocante à estratégia literária, quanto também no aspecto do arrefecimento do conteúdo pessimista. Nele, por um lado, Schopenhauer opta pela argumentação pautada em aforismos - cuja estrutura argumentativa não se orienta por deduções lógico-sistemáticas, mas como veremos, por uma argumentação que remonta à plausibilidade, à autorreferencialidade das ideias, vislumbrando um aspecto performático do texto. Por outro lado, o texto dos Aforismos parece mostrar um horizonte autogenealógico do filósofo, ou seja, o momento quando uma filosofia se autorreflete sobre seu próprio autor, ou ainda, quando Schopenhauer executa em ato uma filosofia que é levada às suas últimas consequências, precisamente nos Aforismos. Nesse caso, não falamos aqui de um texto autobiográfico, mas sim de um texto autogenealógico tal como explicaremos adiante, que apresenta, também performaticamente, um Schopenhauer arrefecido da carga pessimista anterior.

Os Aforismos exprimem provavelmente o momento extremo em que Schopenhauer se mostra (autodeixis) como Schopenhauer e, por isso mesmo, o texto privilegiado para compreendermos algumas semânticas que giram em torno da sabedoria de vida, uso prático da razão e prudentia. Nesse caso, privilegiando especificamente o texto dos Aforismos, nosso artigo tem a pretensão de indicar algumas hipotéticas chaves de leitura ou horizontes interpretativos, a propósito da noção de prudentia em seu uso prático da razão, entendida como uma sabedoria de vida, como por exemplo, o deslocamento do eixo da sabedoria estoica para as máximas aristotélicas, a noção que denominamos de 'grande pessimismo', o aspecto performático tanto da estratégia literária marcada pela plausibilidade, quanto de um texto autogenealógico. Cada uma dessas chaves de leitura nos servem para esboçar uma semântica possível que o termo prudentia recebe no interior dos Aforismos. Estruturalmente, organizamos o texto de modo a explicar cada hipótese em um tópico específico de discussão.

\section{Duas proposições do caráter adquirido: autoconhecimento e experiência}

Para além de qualquer análise específica sobre o tema do caráter adquirido, gostaríamos de tomar aqui apenas dois aspectos que nos são fundamentais, a fim de analisar nos Aforismos uma interpretação possível da noção de "prudentia" como sabedoria de vida em Schopenhauer. Trata-se da 
noção de autoconhecimento e experiência ${ }^{2}$, que por sua vez podem ser lidos a partir da seção $§ 55$ de O mundo.

Ao lado do caráter inteligível e do caráter empírico, Schopenhauer indica ainda o "caráter adquirido", sobretudo na sua designação compreendida como "o conhecimento mais acabado possível da própria individualidade" ${ }^{3}$ que, nesse caso, alude diretamente também ao autoconhecimento. $\mathrm{Na}$ seção $§ 55$ de $O$ mundo, lê-se:

Ao lado do caráter inteligível e do empírico, deve-se ainda mencionar um terceiro, diferente dos dois anteriores, a saber, o caráter adquirido, o qual se obtém na vida pelo comércio com o mundo e ao qual é feita referência quando se elogia uma pessoa por ter caráter, ou se a censura por não o ter. - Talvez se pudesse naturalmente supor que, como o caráter empírico, enquanto fenômeno do inteligível, é inalterável, e, tanto quanto qualquer fenômeno natural, é em si consequente, o homem também sempre teria de aparecer igual a si mesmo e consequente, com o que não seria necessário adquirir artificialmente, por experiência e reflexão, um caráter. Mas não é o caso. Embora sempre sejamos as mesmas pessoas, nem sempre nos compreendemos. Amiúde nos desconhecemos, até que, em certo grau, adquirimos autoconhecimento ${ }^{4}$.

Se por um lado é possível aludir ao autoconhecimento, por outro lado, porém, há que se haver o comércio com o mundo, i.é., uma efetiva travessia e engajamento em situações concretas através das vivências de cada um e, nesse caso, a necessária experiência de vida. Na mesma seção, a esse respeito, escreve Schopenhauer:

Temos primeiro de aprender pela experiência o que queremos e o que podemos fazer: pois até então não o sabemos, somos sem caráter, e muitas vezes, por meio de duros golpes exteriores, temos de retroceder em nosso caminho. - Mas, se finalmente aprendemos, então alcançamos o que no mundo se chama, o caráter adquirido 5 .

Autoconhecimento e experiência pressupõem tanto a vivência efetiva engajada no mundo, quanto também a reflexão de quando em quando sobre tais vivências, logo, uma certa estruturação teórica de tal matéria-prima vivenciada, que pode muito bem ser convertida em autoconhecimento.

A ponte de ligação entre $O$ mundo e os Aforismos a propósito do tema é precisamente o aforismo 30 das 'Exortações e máximas', onde Schopenhauer emprega a expressão textualmente. Nesse caso, escreve Schopenhauer nos Aforismos, "nenhum caráter é de tal modo talhado que possa

\footnotetext{
${ }^{2}$ Sobre a discussão do caráter adquirido na direção que vai de $O$ mundo até os Aforismos, cf. DEBONA, Vilmar, Schopenhauer e as formas da razão. São Paulo: Annablume, 2010, pp. 66-76.

${ }^{3}$ SCHOPENHAUER, A. MVR, p. 393s.

${ }^{4}$ Idem, p. 391.

${ }^{5}$ Idem, p. 393.
} 
ser abandonado a si mesmo [...], mas cada um precisa ser guiado por conceitos e máximas”, de modo que é possível pensar um caráter não apenas como "o produto da nossa natureza inata, mas apenas da ponderação racional, logo um caráter inteiramente adquirido [...]"6. Nesse aforismo, Schopenhauer enfatiza uma espécie de cultivo de si, ou "adestramento de si", algo como o longo exercício que fazemos conosco mesmo no comércio com o mundo, até aos poucos aprendermos a conjugar aquilo que em nós é inato, com o uso prático disso na efetividade do mundo:

\begin{abstract}
Nesse caso, dá-se o mesmo que em todas as prescrições e instruções teóricas para uso prático: compreender a regra é o primeiro passo, o segundo é aprender a aplicá-la. A compreensão é adquirida de uma só vez pela razão [o guiar-se por máximas e conceitos - JLV], o aprendizado é absorvido aos poucos pelo exercício. [...] Não é de outra maneira que o rústico se torna um cortesão, o colérico, um fino homem do mundo [...]. Mas esse adestramento de si mesmo, resultado do longo hábito, sempre fará efeito como uma coerção vinda de fora, contra a qual a natureza nunca cessa de resistir, às vezes violando-a inesperadamente ${ }^{7}$.
\end{abstract}

Chamemos atenção à expressão "adestramento de si mesmo" como "resultado do longo hábito". Schopenhauer se refere aí precisamente a uma técnica de construção de si mesmo, no rigoroso sentido da trajetória de alguém para tornar-se aquilo que se é. Além disso, a ênfase no caráter adquirido ocorre nos Aforismos também de modo indireto, p.ex., quando Schopenhauer o relaciona com as respectivas idades da vida. Isso significa que adquirimos um caráter, sempre a partir do confronto e comércio com o mundo, num gradativo processo que, segundo Schopenhauer, culmina na velhice: "Fiz a observação de que o caráter de quase todo homem parece adaptar-se mais adequadamente a uma determinada idade da vida, de modo que é nela que cada um se apresenta de modo mais favorável. [...] Muitos apresentam-se da melhor maneira possível na velhice, quando são serenos, porque têm mais experiência e calma [...]. Tal peculiaridade deve resultar do fato de que o próprio caráter tem algo de juvenil, viril ou senil, em concordância com a idade correspondente ou corrigido por ela"s.

Tanto em $O$ mundo quanto nos Aforismos os horizontes do autoconhecimento e da experiência se conjugam especificamente no caráter adquirido: a ênfase numa técnica de cultivo de si mesmo, que consiste na lenta e gradual escalada de uma sabedoria de vida.

\footnotetext{
${ }^{6}$ SCHOPENHAUER, A. P/ Aforismos para a sabedoria de vida, p. 215.

${ }^{7}$ Idem, p. 216.

${ }^{8}$ Idem, p. 260. 


\section{Da sabedoria estoica às máximas aristotélicas}

Uma característica marcante nos Aforismos para sabedoria de vida e fundamental para o sentido de prudentia, o uso prático da razão entendido como sabedoria de vida, tal como logo veremos, é o deslocamento do apreço schopenhaueriano da "sabedoria estoica" no Mundo como vontade e como representação, para o flerte com as máximas aristotélicas nos Aforismos. Isso não significa dizer que Schopenhauer abandona o horizonte da sabedoria estoica, e se torna aristotélico. Aliás, ele não é nem um e nem outro: Schopenhauer é sempre Schopenhauer! O que queremos dizer é que ele ainda permanece na esteira do espírito da sabedoria estoica, no rigoroso sentido que se preocupa muito mais com uma 'sabedoria de vida' oriunda de uma técnica sobre si mesmo, e nada enfático quanto a uma "doutrina de virtudes"; porém, nos Aforismos, além disso, ele desloca esse eixo da sabedoria estoica e operacionaliza máximas aristotélicas como lente de aumento para exprimir seus próprios pensamentos.

De forma específica, encontramos no $\S 16$ de $O$ mundo o elogio da "sabedoria estoica", na medida em que se pauta não na construção da virtude, mas no emprego da razão no mundo prático para dirimir a dor e o sofrimento: "Pois a ética estoica não é originária e essencialmente uma doutrina da virtude, mas mera instrução para uma vida racional, cujo fim e objetivo é a felicidade mediante a tranquilidade de ânimo". . Essa filosofia prática, porém, possui uma contradição que Schopenhauer já aponta à época de $O$ mundo, pois "falta muito para que algo perfeito seja trazido a bom termo por essa via, e, assim, de fato, a razão, corretamente empregada, possa livrar-nos de todo fardo e sofrimento da vida [...] Antes, verifica-se uma completa contradição em querer viver sem sofrer, contradição que também se anuncia com frequência na expressão corrente "vida feliz"" ${ }^{10}$. Assim é que, nos Aforismos, emprega-se o mesmo espírito da época estoica da 'instrução para a vida', nesse caso, mediante a 'sabedoria de vida' ou uma prudentia para se atingir uma vida 'menos infeliz', porém, o eixo se desloca dos estoicos e se assenta nas máximas aristotélicas, sem recair, porém, em uma 'doutrina da virtude'. Se o sábio estoico, em $O$ mundo, não sabe “onde ir com sua sabedoria”, assim escreve Schopenhauer, de modo que "nunca pôde ganhar vida ou verdade poética interior, mas permaneceu um boneco de maneira com o qual não se pôde fazer nada" "11, nos Aforismos, porém, trata-se de empregar o espírito da prudentia ou fazer uso prático da razão para uma vida "menos infeliz"12.

\footnotetext{
${ }^{9}$ SCHOPENHAUER, A. MVR, p. 142.

${ }^{10}$ Idem, p. 147.

${ }^{11}$ Idem, p. 148.

${ }^{12}$ SCHOPENHAUER, A. P/ Aforismos para a sabedoria de vida, p. 141. Cf. também sobre o tema, BARBOZA, Jair. Uma terapia para ser menos infeliz no inferno. In: Adverbum (Campinas, Online). v. 3, 2008, p. 119-124.
} 
Nos Aforismos, Schopenhauer cita Aristóteles 18 vezes, e todas de modo sumariamente positivo, inclusive, tomando suas máximas como premissas à sua própria argumentação. Para fins ilustrativos, tomemos aqui duas hipóteses cardeais presentes nos Aforismos que Schopenhauer operacionaliza de Aristóteles. Por um lado, a própria tripartição dos bens humanos que dá o tom à organização do livro. Citando a Ética a Nicômaco, Schopenhauer conserva essa tripartição aristotélica, tomando-o como lente de aumento para exprimir seu próprio pensamento, vale dizer, "o que alguém é [...]; o que alguém tem [...]; o que alguém representa" ${ }^{\prime 13}$. Por outro lado, lembremos também da 'máxima geral' expressa no capítulo 'Exortações e máximas' dos Aforismos, cuja sentença é considerada por Schopenhauer como "regra suprema de toda sabedoria de vida". Ali o filósofo cita novamente a Ética a Nicômaco (VII, 12), especialmente a máxima que reza: “O prudente aspira não ao prazer, mas à ausência de dor." Independente do fato de se a interpretação que Schopenhauer faz do texto aristotélico é correta ou não, importa é que ele o instrumentaliza para exprimir sua máxima geral do livro, escrita sob a fórmula "viver menos infeliz, ou seja, de modo suportável"14. A regra aristotélica, pois, é empregada no texto schopenhaueriano na medida em que precisamos "direcionar nossa atenção não para os prazeres e comodidades da vida, mas para escapar, tanto quanto possível, dos seus inumeráveis males" ${ }^{15}$. Nesse caso, o que menos importa é, como já dissemos, se é válida ou não a interpretação da letra aristotélica. Aliás, Schopenhauer comete sim alguns deslizes exegéticos ao lançar mão do texto de Aristóteles. Ora, todo grande filósofo parece ser um mau leitor, de modo que não o é diferente no caso de Schopenhauer. Por isso mesmo, ele apenas instrumentaliza, operacionaliza ou faz uso do texto aristotélico em seus próprios interesses, inclusive deslocando semânticas ou resignificando certos conceitos.

Em suma, se o eixo é deslocado da sabedoria estoica às máximas aristotélicas nos Aforismos, isso significa que Schopenhauer faz uso não do horizonte da ética aristotélica, pautada na construção da assim denominada excelência moral, mas muito mais instrumentaliza suas máximas, empregando-as como lente de aumento para que ele exprima seus próprios pensamentos, a sua própria sabedoria de vida, que por sua vez, ainda conserva o espírito de uma sabedoria de instrução para a vida, sem recair em uma 'doutrina de virtudes'. Assim, por um lado, Schopenhauer é sempre Schopenhauer tanto porque se distancia da contradictio in adjecto da sabedoria estoica, "a expressão

\footnotetext{
${ }^{13}$ SCHOPENHAUER, A. P/ Aforismos para a sabedoria de vida, p. 3.

${ }^{14}$ Idem, p. 141. No texto de Aristóteles, lemos: "Os argumentos baseados nas premissas de que o homem temperante evita os prazeres, e de que o homem dotado de sabedoria prática busca a vida sem dor" (ARISTÓTELES, EN VII, 12, 1153a 26-28).

${ }^{15}$ Idem, ibidem. Outros temas dos Aforismos também são indiretamente devedores de Aristóteles, como os bens exteriores entendidos como 'mediações' para o mundo (p. 13-15), a consideração de que a fonte da felicidade é a individualidade (p. 32s.), a noção do bastar-se a si mesmo (p. 161), a importância da felicidade oriunda também de um operar, um construir pela ação, pelo 'fazer' (p. 190s.), a hipótese do 'adestramento de si', como veremos adiante, um exercício "resultado do longo hábito" (p. 216), ou ainda, a ideia de que nos tornamos efetivamente prudentes à medida que adquirimos a experiência que só o tempo nos pode dar (p. 263).
} 
corrente 'vida feliz"”, quanto também porque não remonta a uma 'doutrina de virtudes', mas sim emprega as máximas aristotélicas como semiótica para seus próprios pensamentos. Por outro lado, é flagrante o deslocamento efetivo dos estoicos para as máximas de Aristóteles.

\section{Do pessimismo ao grande pessimismo}

O texto dos Aforismos também representa, a nosso ver, o momento extremo da autorreflexão de uma filosofia sobre seu próprio autor. De modo algum falamos de um texto autobiográfico, mas uma espécie de autogenealogia cujos horizontes filosóficos anteriores servem como as condições genealógicas para compreender como certos pensamentos nascem e se desenvolvem. Assim é que no texto dos Aforismos, Schopenhauer também executa a trajetória que vai de um "ponto de vista superior, ético-metafísico"16 típico do pessimismo de $O$ mundo, para aquilo que denominamos de 'grande pessimismo"17, i.é., uma "acomodação" na vida que faz o autor se distanciar de um pessimismo absoluto, para vislumbrar as possibilidades de 'viver menos infeliz'. O 'grande pessimismo' é a prerrogativa daquele que agora pode executar em si as possibilidades de uma vida 'menos infeliz', somente porque vivenciou até a medula o próprio pessimismo, ou se quisermos, um 'otimismo prático' que é o privilégio daquele que foi suficientemente pessimista, experimentando cada um dos seus padecimentos na própria carne.

Permanecendo ainda no âmbito da “imanência”, o 'grande pessimismo' de Schopenhauer o faz definir sua "sabedoria de vida" como "a arte de conduzir a vida do modo mais agradável e feliz possível”18. Numa argumentação de caráter aforismática, a marca do texto dos Aforismos, ele exerce o papel de médico de si mesmo, cujo 'grande pessimismo' não consiste mais nas hipóteses de negação do querer viver, mas do distanciamento do mundo e dos outros, voltando-se para si mesmo a fim de esboçar as possibilidades de uma vida 'menos infeliz'. Sua argumentação não é mais orientada sistematicamente, de modo a deduzir conceitos a partir de certas premissas, mas remonta à estrutura aforismática pautada no argumento de plausibilidade. Plausível é aquilo que não necessita de demonstrações posteriores - uma argumentação típica da estrutura aforismática -, cujas ideias são autorreferenciais, de modo que o plausível também exprime mais o caráter performático do texto do que um rigor dedutivo-conceitual: o autor não está mais interessado em acertar contas consigo mesmo ou com outras tradições filosóficas, mas uma espécie de descanso de si mesmo, cujas ideias agora são esboçadas por alguém que já se coloca ao longe, distanciado de certas situações e detentor de uma

\footnotetext{
${ }^{16}$ Idem, p. 2.

${ }^{17} \mathrm{O}$ tradutor do livro, Jair Barboza, denomina esse deslocamento de um "otimismo prático" (cf. a Apresentação do livro, p. $\mathrm{XIII)}$.

${ }^{18}$ SCHOPENHAUER, A. P/ Aforismos para a sabedoria de vida, p. 1.
} 
visão panorâmica sobre sua trajetória de vida bem como sobre si mesmo. Assim, a definição schopenhaueriana de 'sabedoria de vida' como condução de vida da forma 'mais agradável e feliz possível' é, nesse aspecto, precisamente um argumento marcado pela plausibilidade, logo, um argumento que não é sustentado dedutivamente, mas muito mais performaticamente apresentado sem posteriores fundamentações. "Uma existência feliz", escreve Schopenhauer, "deixa-se definir considerada de modo puramente objetivo ou, antes, pela ponderação fria e madura [...] - como algo que seria preferível à não-existência." Não se trata, então, de ansiar uma vida 'menos infeliz' por conta do medo da morte, e nem mesmo deduzir essa existência tomando a morte como interlocutora, mas apenas pelo diagnóstico plausível de que "nos apegamos a ela [uma existência feliz - JLV] por ela mesma, não meramente pelo medo da morte"19.

A argumentação marcada pela plausibilidade de uma 'existência feliz' ou uma vida 'menos infeliz' se basta por si mesma, ela é autorreferencial. Mas aqui está nosso ponto: é uma argumentação que representa uma filosofia que foi levada às suas últimas consequências, realizando um ato de autorreflexão sobre seu próprio autor; um pessimismo levado às suas últimas consequências, até realizar sobre seu autor o ato do 'grande pessimismo', ou um 'otimismo prático' que é prerrogativa daquele que vivenciou até a medula seu próprio pessimismo, mas que agora ganhou uma visão panorâmica a ponto de conquistar uma 'acomodação', ou sabedoria prática em meio à "dor e o tédio" que são "os dois inimigos da felicidade humana" 20 . O 'grande pessimismo' daquele que conquistou experiência e autoconhecimento, a fim de fazê-los voltar sobre si próprio, ou realizar na carne sua própria filosofia: "Nossa experiência pessoal", escreve Schopenhauer nos Aforismos, "também pode ser vista como um texto, do qual a reflexão e o conhecimento são o comentário"21.

Assim, por um lado, se a estratégia literária dos Aforismos remonta à plausibilidade, indicando seu aspecto performático do texto - pois enfatiza mais a autorreferencialidade plausível da argumentação e não sua dedução - o 'grande pessimismo', por outro lado, indica também a performatividade do seu próprio autor. Nesse caso, tão logo observamos a autorreflexão de uma filosofia sobre seu próprio autor nos Aforismos, isso também significa, simultaneamente, que o próprio autor se mostra (autodeixis) performaticamente, isto é, sem precisar escrever ou justificar-se a si mesmo numa autobiografia, mas apenas mostrando-se performaticamente no momento mesmo em que executa a autorreflexão da sua filosofia sobre si mesmo, ou seja, o momento do seu 'grande pessimismo'.

\footnotetext{
${ }^{19}$ Idem, p. 1.

${ }^{20}$ Idem, p. 24.

${ }^{21}$ Idem, p. 160. 


\section{Sobre a noção de 'uso prático' da razão e a prudentia como sabedoria de vida}

A expressão 'uso prático' da razão se justifica a partir de dois horizontes bem específico dos Aforismos: por um lado, Schopenhauer está absolutamente ciente da hipótese de que o curso da vida se desdobra a partir de nossas vivências e, enquanto tal, desdobra-se como pathos, de modo que nunca estamos conscientes do pathos próprio da vida, enquanto nela nós estamos, ou seja, nunca somos absolutamente conscientes daquilo que vivenciamos, no instante mesmo em que vivenciamos: “Assim como o trabalhador que ajuda a erguer um edifício não conhece o plano do conjunto ou não o tem sempre presente, o mesmo também se dá com o homem enquanto consome cada dia e cada hora de sua existência, em relação ao conjunto e ao caráter de sua vida"22. Dessa forma, tal como o andarilho que precisa subir num cume para ter uma visão panorâmica do seu caminho, "nós também só reconhecemos a verdadeira concatenação de nossas ações [...] ao final de um período de nossa vida ou até mesmo da vida inteira" ${ }^{23}$.

Por outro lado, esse caráter pathetico do comércio com o mundo acaba por justificar ainda mais o 'uso prático' da razão, um certo discernimento pragmático cuja atuação no mundo se dá sempre naquilo que, em alemão, podemos chamar de Spielraum - termo esse também empregado por Schopenhauer -: um espaço delimitado, de comportamentos desregulados ${ }^{24}$, numa espécie de somatória entre "a série dos acontecimentos" - que nos são sempre inconscientes no instante em que vivenciamos -, e "nossas decisões", nosso uso prático em situações sempre concretas, ou ainda “tomar decisões sempre segundo a medida das circunstâncias" que são, porém, sempre incertas e incontroláveis ${ }^{25}$. E aqui é que se justifica o apreço schopenhaueriano pelo espírito da "sabedoria estoica", ou pelo sentido de uma "sabedoria de vida" no geral, quer dizer, uma sabedoria que não remonta a uma "doutrina da virtude, mas mera instrução para uma vida racional" ${ }^{26}$. Tal sabedoria de vida, tem de compreender que "o destino embaralha as cartas, e nós jogamos", mais ou menos como em um jogo de xadrez: "esboçamos um plano que, todavia, fica condicionado à vontade do adversário, no jogo, e à do destino, na vida. As modificações sofridas pelo plano são, na maior parte das vezes, tão grandes, que é difícil reconhecê-lo, durante a execução, em alguns dos seus traços fundamentais" ${ }^{27}$.

\footnotetext{
${ }^{22}$ Idem, p. $152 \mathrm{~s}$.

${ }^{23}$ Idem, p. 153.

${ }^{24}$ Cf. STEGMAIER, W. Philosophie der Orientierung, p. 221.

${ }^{25}$ Cf. SCHOPENHAUER, A. P/ Aforismos para a sabedoria de vida, p. 234.

${ }^{26}$ SCHOPENHAUER, A. $M V R$, p. 142.
}

${ }^{27}$ SCHOPENHAUER, A. P/ Aforismos para a sabedoria de vida, p. 234s. Isso significa que ela sempre se desdobra no mundo. Além disso, trata-se de um uso pragmático da razão, na medida em que, através da experiência e autoconhecimento, conseguimos empregá-la a uma acomodação na vida, intuito de uma vida menos infeliz. Assim é o que se fala da velhice, pois apesar do caráter ser imutável, o intelecto é mutável para fazermos uso no mundo prático: “Deve-se notar sobretudo que, embora o intelecto, ou a cabeça, seja inato nas suas qualidades fundamentais, tanto quanto o caráter ou o coração humano, de modo algum permanece tão imutável quanto estes, mas está sujeito a muitas transformações que, em conjunto, aparecem regularmente [...] o conteúdo do pensar e do saber, a experiência, os conhecimentos, o exercício e a 
A noção, pois, de 'uso prático' da razão se justifica na medida em que conjugamos tanto o curso pathetico das nossas vivências nos acontecimentos, sempre incertos e inconscientes para nós - e isso justificaria também agirmos como o andarilho que de quando em quando sobe ao cume para ganhar uma visão geral do seu caminho, ou seja, é preciso dar por vezes um "pequeno passo no conhece-te a ti mesmo"28 -, quanto também nossas decisões nas situações concretas do mundo, quando agimos sempre em espaços determinados (situações concretas), levando em conta os horizontes imprevisíveis (a vontade do adversário e o acaso da vida) tal como o jogo de xadrez (Spielraum). Uma sabedoria de vida emprega nesse sentido a razão, praticamente.

A partir desse ponto de vista, arriscamos aqui um esboço para o conceito de prudentia em Schopenhauer, rubrica esta que legitima a noção de uso prático da razão, no sentido de uma 'sabedoria de vida'. Foi em $O$ mundo como vontade e como representação, especialmente na sua Crítica da filosofia kantiana, que Schopenhauer associou diretamente os conceitos de razão prática e prudentia: "O que nesse sentido se chama razão prática", escreve ele, "é muito aproximadamente designado pela palavra latina prudentia"29. Contudo, queremos enfatizar aqui que Schopenhauer não está vinculado à

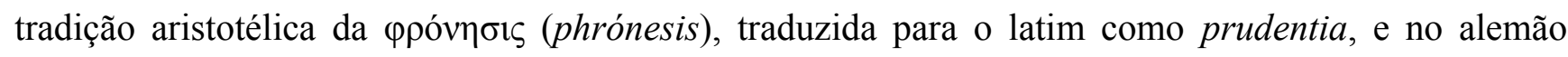
como Klugheit ${ }^{30}$. Mais do que isso, trata-se apenas de empregar um conceito corrente do vocabulário filosófico, a prudentia, mas ter em mente que o interpretamos num sentido muito específico no interior dos Aforismos. Desse modo, não significa aqui vincular Schopenhauer a qualquer tradição ética específica, mas sim de compreender como é possível esboçar um conceito possível do filosofema prudentia, a partir do uso mesmo que esse vocábulo recebe no texto de 1851.

O mais correto seria, pois, falar da noção de prudentia no interior do horizonte semântico schopenhaueriano dos Aforismos que, por um lado e latu sensu, pode ser designado como 'sabedoria de vida'. Porém, nos Aforismos, por outro lado, essa prudentia também pode ser compreendida, stricto sensu, a partir daquilo que definimos como diferenciação da diferenciação. Trata-se do procedimento específico para a "acomodação" em meio às dores e aos sofrimentos do mundo, ou uma sabedoria de vida que consiste em confrontar-se com o mundo e com os outros, diferenciando-os cada um em sua particularidade, ponderando suas banalidades ou tolices, para então, ao cabo do desdobramento de um percurso de vida, diferenciar-se a si mesmo em relação àquilo que foi diferenciado. Uma dupla diferenciação, isto é, uma diferenciação da diferenciação. Assim é que se justificam as duas instâncias

perfeição da intelecção resultante - é uma quantidade que cresce continuamente [...] O fato de o homem consistir numa parte absolutamente imutável [caráter] e em outra regularmente mutável [intelecto] [...] explica a diversidade de sua manifestação e de sua validade nas diferentes idades da vida" (Idem, p. 265s).

${ }^{28}$ Idem, p. 153.

${ }^{29}$ SCHOPENHAUER, A. MVR, p. 644.

${ }^{30}$ Cf. WIEDMANN, F./ BILLER, G. "Klugheit”. In: RITTER, Joachim (Hrsg.) Historisches Wörterbuch der Philosophie. Band 4. Basel/Stuttgart: Schwabe \& Co. Verlag, 1972, p. 857-863. 
cruciais do caráter adquirido: o autoconhecimento e a experiência. A experiência para poder ser capaz de ver nuance e diferenças no mundo e com os outros, e autoconhecimento para poder refletir sobre aquilo que foi diferenciado, cujo autoconhecimento corresponde precisamente àquele distanciamento do andarilho para ganhar uma visão panorâmica da sua trajetória. A prudentia como diferenciação da diferenciação, porém, intensifica a noção de Besonnenheit, na medida em que se trata do uso prático da razão em seu momento extremo, ali quando Schopenhauer se diferencia como Schopenhauer, em relação àquilo que ele diferenciou no mundo e nos outros por conta do comércio com o mundo e com os outros. Assim, se por um lado é sempre a vontade ainda que conduz a trajetória de vida e o agir mesmo nessa trajetória, sem uma determinação da razão, por outro lado, porém, o uso prático da razão é o horizonte da prudentia, i.é., quando Schopenhauer emprega praticamente a razão em proveito de uma vida 'menos infeliz'. Esse emprego prático e prudente da razão, portanto, caracteriza a intensificação da Besonnenheit, ou o momento específico em que o próprio Schopenhauer agora se diferencia como Schopenhauer, num distanciamento em relação ao que ele diferenciou no mundo e nos outros, através das suas vivências.

Schopenhauer remete à velhice a principal prerrogativa dessa prudentia, no rigoroso sentido que estamos explicando - talvez não à toa o texto dos Aforismos seja um dos últimos publicados pelo filósofo. É na velhice que se conquista uma visão geral da existência, quando se pode diferenciar cada situação ponderando-as, para depois ponderar-se a si mesmo nas ponderações feitas: "É a partir desse momento que a experiência e erudição se tornam de fato ricas", escreve Schopenhauer: "teve-se tempo e oportunidade para considerar e refletir as coisas sob todos os aspectos, comparando-as entre si e descobrindo os seus pontos de contato e membros conectivos; por conseguinte, apenas nesse momento as compreendemos bem em toda a sua concatenação. [...] Apenas quem envelhece adquire uma ideia completa e perfeita da vida, pois tem uma visão geral do seu conjunto e do seu curso natural e, em especial, porque não a vê como os outros, ou seja, apenas a partir do ponto de entrada, mas também a partir do ponto de saída [...]"31.

O uso prático da razão, porém, já se encontra também em outros lugares do texto, p.ex., quando precisamos dar uma olhada naquilo que vivenciamos para analisar o conjunto de nossa trajetória aventuresca $^{32}$. Aquele pequeno passo no 'conhece-te a ti mesmo' é a circunstância favorável, a ponderação aconselhável para ganharmos uma visão panorâmica: “só o resultado nos mostrará o que adveio de tudo isso, e só o olhar lançado para trás sobre o conjunto nos mostrará o como e o modo pelo qual" ${ }^{\prime 3}$. Contudo, a sabedoria de vida que diferencia a si mesmo, em relação ao que diferenciou no mundo e nos outros, parece culminar, de fato, justamente na velhice, o momento específico da

\footnotetext{
${ }^{31}$ SCHOPENHAUER, A. P/ Aforismos para a sabedoria de vida, p. 264.

${ }^{32}$ Cf. Idem, p.ex. p. 153 e 234.

${ }^{33}$ Idem, p. $153 \mathrm{~s}$.
} 
prudentia: “O mais estranho, porém, é que só no fim da vida conseguimos reconhecer e compreender propriamente a nós mesmos, bem como nossas metas e nossos objetivos, sobretudo em nossas relações para com o mundo e os outros. [...] Aprendemos qual é o valor de cada um" ${ }^{34}$. Essa é a prudentia que o ancião conquista, "em parte", como escreve Schopenhauer, "porque a experiência nos esclareceu sobre o valor das coisas e o conteúdo dos prazeres, isentando-nos gradualmente das ilusões, das quimeras e dos preconceitos que outrora encobriam e distorciam a visão livre e limpa das coisas. [...] É justamente isso que dá a quase todo ancião [...] certo ar de sabedoria, distinguindo-se dos jovens. Mas o principal resultado de tudo é a tranquilidade espiritual, que é um elemento importante da felicidade" 35 . Observe-se nessa passagem que se trata do instante quando se consegue compreender o 'valor das coisas' para ponderá-las, ou seja, o momento quando é possível fazer uso prático da razão para se diferenciar em relação às diferenciações das coisas, do mundo e dos outros. Se quisermos emprestar uma fórmula nietzscheana para isso ${ }^{36}$, podemos sim dizer que também se trata de um momento genealógico, ou no caso de Schopenhauer, de uma autogenealogia, quando o próprio Schopenhauer agora compreende o valor dos valores, o valor dos valores das coisas, o valor dos valores do mundo e dos outros, para então distanciar-se e diferenciar-se como Schopenhauer. A finalidade dessa prudentia é aquela de uma vida 'menos infeliz', uma "raposa velha" tal como o adjetivo que Schopenhauer confere ao homem "prudente": "Devemos, antes, como um prudente, praticar o máximo possível a cautela, prevenindo e alijando acidentes, quer eles venham dos homens ou das coisas, e nos aperfeiçoar bastante nessa arte, para assim, como raposa velha, desviarmo-nos de todo grande ou pequeno infortúnio"37 e além disso, alguém que "jamais hesitasse por indecisão e nunca agisse por precipitação"38.

A trajetória argumentativa dessa forma schopenhaueriana de sabedoria de vida, isto é, aquela prudentia compreendida como diferenciação da diferenciação, parte, pois, da máxima suprema dessa sabedoria explicada logo no aforismo 1 das 'Exortações e máximas', vale dizer, a máxima aristotélica de que "o prudente aspira não ao prazer, mas à ausência de dor", e que se converte no mote central dos Aforismos sob a fórmula, "viver menos infeliz"39, até ganhar corpo por completo, ou seja, praticamente, na prudentia típica da velhice, quando, tal como escreve Schopenhauer, "se sabe melhor prevenir as desgraças" ${ }^{\prime 40}$. O procedimento prudente de diferenciar-se a si, naquilo que diferenciou

\footnotetext{
${ }^{34}$ Idem, p. 266.

${ }^{35}$ Idem, p. 269.

${ }^{36}$ Referimo-nos aqui à noção mesma de genealogia em Nietzsche, entendida como a pergunta pelo "próprio valor desses valores". (cf. NIETZSCHE, F. Genealogia da moral. Prólogo, § 6. Trad. Paulo César de Souza. São Paulo: Companhia das Letras, 1998).

${ }^{37}$ SCHOPENHAUER, A. P/ Aforismos para a sabedoria de vida, p. 241.

${ }^{38}$ Idem, p. 244.

${ }^{39}$ Idem, p. 141.

${ }^{40}$ Idem, p. 267.
} 
durante a vida, reconhecendo o valor de cada coisa, é o instante daquilo que denominamos de 'grande pessimismo', o privilégio daquele que só pode menos infeliz, ao preço de ser suficientemente pessimista, ou ser 'otimista prático', ao preço de se ganhar aquela saudável distância novamente do mundo e dos outros, reconhecendo o padecimento sôfrego de uma trajetória e, ao cabo dela, diferenciar-se a si numa certa leveza novamente diante da vida. Esse movimento sábio da prudentia está registrado sob a fórmula: "a velhice tem a serenidade daqueles que, livres dos ferros há muito suportados, podem enfim movimentar-se com liberdade" ${ }^{41}$.

A contradictio in adjecto encontrada por Schopenhauer em 1818 na sabedoria estoica e formulada sob a expressão "vida feliz"42 é apaziguada em 1851 sob a máxima suprema da sua sabedoria de vida, vale dizer, "viver menos infeliz", quando o próprio Schopenhauer realiza em si mesmo seu próprio ato da prudentia, é esse Schopenhauer que conquista em si próprio a prerrogativa do 'grande pessimismo', o mais genuíno privilégio daquele que pode ser otimista, ao preço de ser suficientemente pessimista, porque agora sabe do valor da existência, mas sabe se 'acomodar' novamente diante do mundo. Um 'grande pessimismo' que é sinônimo da autorreflexão de uma filosofia sobre seu próprio autor, quando o próprio Schopenhauer se diferencia prudentemente como Schopenhauer, relativamente ao que diferenciou.

\section{O mundo e o outro como semiótica para si mesmo}

Ao partir de Aristóteles para dividir os bens humanos, Schopenhauer atribui ocupar o primeiro lugar precisamente "o que alguém é: portanto, a personalidade no sentido mais amplo" "43, de modo que aquilo que já possuímos em nós e que nos foi dado pela natureza é superior ao que "alguém tem", bem como ao que "alguém representa". Nesse aspecto, a "individualidade determina de antemão o grau de sua felicidade possível"44, de modo que, tal como arremata Schopenhauer, "o que alguém tem em si mesmo é o que há de mais essencial para a sua felicidade de vida" ${ }^{\text {45 }}$. Schopenhauer chega até mesmo a dizer que "o homem é muito menos passível de ser modificado pelo mundo exterior do que se supõe"

\footnotetext{
${ }^{41}$ Idem, p. 268. Sobre o tema da relação entre liberdade e sabedoria prática, cf. CHEVITARESE, Leandro. $A$ ética em Schopenhauer: que "liberdade nos resta" para a prática de vida?. (Tese de doutorado), Pontifícia Universidade Católica do Rio de Janeiro. Rio de Janeiro, 2005.

${ }^{42}$ SCHOPENHAUER, A. MVR, p. 147.

${ }^{43}$ SCHOPENHAUER, A. SCHOPENHAUER, A. P/ Aforismos para a sabedoria de vida, p. 3.

${ }^{44}$ Idem, p. 7.

${ }^{45}$ Idem, p. 13. Cf. também p. 30. Schopenhauer escreve ainda: "Portanto, os bens subjetivos, tais como um caráter nobre, uma mente capaz, um temperamento feliz, um ânimo jovial e um corpo bem constituído e completamente saudável - logo, de modo geral, mens sana in corpore sano (Juvenal, Sát. X, 356) - são o que há de primário e mais importante para a nossa felicidade" (idem, p. 16). Entretanto, e de modo ainda bem aristotélico, Schopenhauer não elimina por completo os bens exteriores, inclusive atribuindo-os sua devida importância (p. 13s.), mas considerando-os sempre num valor "mediato" (idem, p. 15).
} 
(idem, p. 10), sendo necessário a ele fazer uso prático da sua razão em torno da sua "personalidade, tal qual nos foi dada, para os maiores proveitos possíveis" ${ }^{\text {46 }}$, ou seja, para 'vida menos infeliz'47.

Esse horizonte da fonte principal da vida menos infeliz, por um lado, corrobora com a noção que explicamos sobre o uso prático da razão em Schopenhauer, na medida em que, nesse ponto, cabe a cada um ser o doador de sentido num mundo absurdo de dor, tédio e tolices. Um ânimo pleno de “jovialidade" é mais hábil para construir algum tipo de sentido, justamente por ter mais riquezas interiores e, portanto, um melhor doador:

Pois o mesmo evento, que se expõe de modo tão interessante numa mente espiritualmente rica, seria, se concebido por uma mente cotidiana e trivial, apenas uma cena insípida do mundo cotidiano. [...] Do mesmo modo, o melancólico vê uma cena trágica onde o sanguíneo assiste apenas a um conflito interessante e o fleumático a algo insignificante ${ }^{48}$.

Aquilo que somos, portanto, dá o tom e a habilidade para doar sentido, ou para fazer uso prático da razão, do contrário, se a "individualidade é de má qualidade, então todos os deleites são como vinhos deliciosos numa boca impregnada de fel"49. Por outro lado, porém, pode parecer uma contradição com nosso esboço da prudentia como diferenciação da diferenciação. Ora, se aquilo que já somos é a fonte principal para a vida menos infeliz, o comércio com o mundo e com os outros é, inclusive, algo a ser evitado por cada um, de modo que não haveria qualquer importância e necessidade em estar no mundo para diferenciá-lo, e somente depois diferenciar a si em relação a isso que foi diferenciado. Assim, o mundo e os outros apenas atrapalhariam a vida 'mais agradável e feliz possível'.

Essa contradição, porém, é apenas aparente. Nossa hipótese em relação a isso, ao contrário, é que, a despeito da atribuição ao que já somos como a fonte principal da vida menos infeliz, os outros e o mundo funcionam como uma semiótica para que possamos voltar a nós mesmos. A estrutura do texto dos Aforismos para sabedoria de vida está toda ela pautada precisamente no consórcio do homem consigo mesmo, com os outros e com o mundo, inclusive porque Schopenhauer também divide dessa maneira os capítulos. O maior capítulo, aliás, é intitulado 'Daquilo que alguém representa', e traz uma ampla análise do nosso consórcio com os outros, sobretudo da representação que os outros fazem de

\footnotetext{
${ }^{46}$ Idem, p. 11.

${ }^{47}$ Ainda flertando com Aristóteles, Schopenhauer escreve que essa noção de que a felicidade se origina da própria interioridade humana, "também encontra sua confirmação na observação bastante justa de Aristóteles, na Ética a Nicômaco (I, 7; e VII, 13, 14), a saber, que todo deleite pressupõe uma atividade, portanto, o emprego de uma força, sem a qual não pode subsistir" (idem, p. 32s.). Para além do fato de se, exegeticamente, Schopenhauer tem razão ou não nesse aspecto, o correto é o quanto ele permanece vinculado às máximas aristotélicas da sabedoria prática.

${ }^{48}$ Idem, p. 5.

${ }^{49}$ Idem, p. 15.
} 
nós, análise essa pautada e dividida em "honra, posição e glória"50. Mas é precisamente nesse mesmo capítulo que lemos a noção schopenhaueriana de que, o pressuposto "para voltar nossa atenção a nós mesmos", tal como ele escreve, é nos confrontarmos com as representações insensatas que os outros fazem de nós, necessariamente. Assim, o pressuposto para 'voltar nossa atenção a nós mesmos' é o procedimento prudente da diferenciação da diferenciação, ou seja, reconhecer as representações insensatas diferencialmente, para depois nos diferenciarmos em relação a essas diferenciações: "O único meio de nos livrarmos dessa insensatez universal", escreve Schopenhauer, "seria reconhecê-la distintamente como tal e, para esse fim, esclarecer para nós mesmos como a maioria das opiniões costuma ser totalmente falsa, invertida, errônea e absurda na cabeça dos homens" ${ }^{\text {" }}$. O senso de realismo de Schopenhauer implica, pois, no fato de que "enquanto vivemos com ou entre os homens" ${ }^{\prime 2}$, tomamo-os como semiótica para nós mesmos, inclusive tomamos as representações que fazem de nós como semióticas para nós mesmos: "E mesmo isso só é levado em conta caso tenha influência sobre alguma coisa que possa modificar aquilo que somos em nós e para nós mesmos" ${ }^{\prime 3}$.

No capítulo das 'Exortações e máximas' esse argumento é arrematado, inclusive quando observamos a própria disposição do texto em subcapítulos intitulados 'Nossa conduta para conosco', 'Nossa conduta para com os outros' e 'Nossa conduta em relação ao curso do mundo e ao destino', ou seja, uma explícita alusão ao comércio com os outros e o mundo, mas justamente no sentido que estamos interpretando, vale dizer, como lente de aumento para si mesmo. Nesses aforismos, p.ex., Schopenhauer reconhece que o caráter é imutável, de modo que "ninguém pode mudar a própria individualidade", logo, "temos de deixar cada um existir como é, aceitando-o em sua individualidade ofertada pela natureza, não importando qual seja”. Se o filósofo já indica aí seu alto grau de realismo, mostra sua habilidade de distanciamento ao reconhecer, por fim, que o mais inteligente é então pensar: Se "não o mudarei, logo, quero usá-1o" 54 , e usá-lo, a nosso ver, como semiótica para si próprio. Nossa hipótese culmina no aforismo 31, onde Schopenhauer fala do outro como um "espelho" para si mesmo: "Entretanto, cada um tem em seu próximo um espelho, no qual vê claramente os próprios vícios, defeitos, maus hábitos e repugnâncias de todo tipo. [...] Quem critica os outros trabalha em prol da própria melhoria. [...] Para nos corrigirmos, precisamos de um espelho" 55 . Nesse mesmo aforismo, além disso, Schopenhauer escreve até mesmo que o comércio com o outro como espelho, ou seja, uma semiótica para mim mesmo, é o procedimento daquele que, como ele escreve, "trabalha na verdade em

\footnotetext{
${ }^{50}$ Idem, p. 73.

${ }^{51}$ Idem, p. 69, o grifo é nosso.

${ }^{52}$ Idem, p. 79.

${ }^{53}$ Idem, p. 63.

${ }^{54}$ Idem, p. $200 \mathrm{~s}$.

${ }^{55}$ Idem, p. 218. 
prol da própria melhoria e do próprio aperfeiçoamento" 56 . Em suma, falamos de uma sabedoria de vida, paradoxalmente, que sobrevém do nosso embate com os outros e com o mundo, para só então ganharmos a prudência da acomodação entre dor e tédio. Assim, se a fonte primeira da felicidade é o que nós somos (algo imutável), o que faz Schopenhauer escrever os aforismos é justamente a contingência do mundo e o comércio com os outros, para que, nesse confronto/distanciamento, possamos voltar-nos a nós mesmos. A sabedoria de vida pressupõe, portanto, tomar o mundo e as representações dos outros como semiótica para nós mesmos, para nossa própria 'acomodação'.

Esses foram alguns horizontes interpretativos para o uso da razão prática nos Aforismos. Não se trata de esgotá-los, pois como o próprio autor escreve, "o tema é inesgotável" ${ }^{57}$. Em todo caso, trata-se apenas de compreender como uma filosofia executa um ato de autorreflexão sobre seu próprio autor, especialmente no tocante à prudentia como uso prático da razão. Nela, Schopenhauer exprime seu 'grande pessimismo', no sentido que explicamos acima, mas sem precisar da negação intransigente ou da afirmação inocente de qualquer pessimismo; o 'grande pessimismo' daquele que conquistou uma sabedoria de vida e, nesse ponto, aquela saudável acomodação realista diante do mundo, que capacita-o a diferenciar-se como Schopenhauer, em relação ao que diferenciou ao longo da vida. Assim é que, para além da negação ou afirmação de qualquer pessimismo, Schopenhauer cita Voltaire ao final da introdução do seu texto: "Deixaremos este mundo tão tolo e tão mau quanto o encontramos ao aqui chegar". Quer dizer, cada um que cultive seu próprio jardim, a fim de ser 'menos infeliz'.

\section{Referências}

ARISTÓTELES. Ética a Nicômaco. In: Os Pensadores. São Paulo: Abril Cultural, 1984.

BARBOZA, Jair. Uma terapia para ser menos infeliz no inferno. In: Adverbum (Campinas, Online). v. 3, p. 119-124, 2008.

29, p. 33-42, 2006.

Modo de conhecimento estético e mundo em Schopenhauer. In: Trans/Form/Ação. v. CHEVITARESE, Leandro. A ética em Schopenhauer: que "liberdade nos resta" para a prática de vida? (Tese de doutorado), Pontifícia Universidade Católica do Rio de Janeiro. Rio de Janeiro, 2005.

DEBONA, Vilmar. Schopenhauer e as formas da razão. São Paulo: Annablume, 2010.

FAUSTINO, S. Schopenhauer, Wittgenstein e a recusa da razão prática. In: Revista de Filosofia, v. 19, n. 25, jul/dez. 2007, p. 255-272.

\footnotetext{
${ }^{56}$ Idem, ibidem. Schopenhauer nesse ponto também cita o exemplo da amizade, cuja censura do amigo é importante para o autoconhecimento: "Os amigos se dizem sinceros; os inimigos os são. Sendo assim, deveríamos usar a censura destes para nosso autoconhecimento, como se fosse um remédio amargo" (idem, p. 222).

${ }^{57}$ Idem, p. 2.
} 
NIETZSCHE, F. Genealogia da moral. Trad. Paulo César de Souza. São Paulo: Companhia das Letras, 1998.

SCHOPENHAUER, A. O mundo como vontade e como representação. Trad. Jair Barboza. São Paulo: Unesp, 2005.

Fontes, 2006. . Aforismos para a sabedoria de vida. Trad. Jair Barboza. São Paulo: Martins

STEGMAIER, W. Philosophie der Orientierung. Berlin/New York: de Gruyter, 2008.

WIEDMANN, F./ BILLER, G. "Klugheit”. In: RITTER, Joachim (Hrsg.) Historisches Wörterbuch der Philosophie. Band 4. Basel/Stuttgart: Schwabe \& Co. Verlag, 1972. 